\title{
The Effect of Computer Games on Students' Performance in Mathematics
}

\author{
Masoud Salimi \\ Department of Psychology, Payame Noor University (PNU), Isfahan, Iran.
}

\section{Doi:10.5901/mjss.2016.v7n3s3p157}

\section{Abstract}

The purpose of this study was to investigate the effect of different kinds of computer games on students' performance in mathematics. To this end, by cluster random sampling method, two schools in Behbahan, Iran, were selected. In each school, two classes were selected by random sampling method $(n=128)$. Data was collected by math tests and structured interview. The sample was divided into two groups: The first group used computer games every day or every other day for half an hour $(n=62)$. The second group didn't use computer games or used them during summer holiday $(n=66)$. The results of independent T-test showed that the average scores of first group $(M=17 / 51)$ were significantly $(p<.001)$ different from the scores of the second group $(M=15 / 42)$. The results also showed that the average scores of group who used war games $(N=35, M=17 / 74)$ were not significantly different from those who used sport games ( $N=27, M=17 / 22)$.

Keywords: computer games, mathematics, computer war games, computer sports games

\section{Introduction}

Video games can attract the attention of the players for a long time and it is called "flow state" and it is full involvement (Kebritchi, Hirumi \& Bai, 2008). The results of a survey show that $90 \%$ of children aged $9-13$ years perform video games. $43 \%$ of children do the games less than one hour and 27\% as 2-6 hours every day (Cited in Jensen 2005/2001). Gunter (1997/2008) states that children at age 6-11 and 12-17 years have the highest number of players.

The inclination of children and adolescents to video games has made the parents concerned. Most of parents state that when they child is involved with a computer game, separating him is difficult. Attraction, frequency and cheap price of computer games on one hand and in our country, the weakness of planning to pass leisure time and shortage of cultural, recreational and sport facilities are the factors increasing the inclination of children and adolescents to computer games. Despite some concerns, some people believe that these games have great facilities for training that should be used. According to Kebritchi et al., (2008), the number of teachers in kindergarten and schools (k-12), universities, army, medicine and hospitals to use games to increase learning is increased. Also, games are effective tools for training complex beliefs as (a), practice is used instead of explanation, (b) it leads to personal satisfaction and motivation, c) various learning skills and styles are presented, d) mastery is improved, e) the texts are presented that are interactive and users can decide themselves (Charles \& McAlister, 2004; Holland, Jenkins \& Squire, 2002). According to Pernsky (2001, cited in Kebritchi et al., 2008), computer games can create new learning culture as adapted with the habits of children and adults.

Aron et al., (1974, cited in Qatrifi, Rashid and Delavar, 2006) state that based on the results of some studies regarding computer games, these games are mostly harmful.

These different statements-positive and negative- regarding the effect of computer games on one hand and increasing inclination of children and adolescents to computer games on the other hand cause that some researchers attempt to define the good and bad effects of these games. The majority of researches are regarding the effect of games on mental health of players, some researchers consider the effect of these games on cognitive and achievement performance of players. According to Ghatrifi et al., (2006) beside all concerns and different views regarding the effect of computer games on psychological state of people, there are some concerns regarding the effect of computer games on academic performance of students. Indeed, one of the first concerns about computer games based on the extension of their use among the youth is that such games by creating an attractive space compared to textbook assignments can lead to interference in scientific and academic performances. The negative effects of computer games on academic performance are supported in some studies. Anderson \& Karen (2002) showed that there was a negative relationship between the duration of computer games and academic performance. Durkin \& Barber (2002) supported the weakness of academic performance of users of computer games. In another study as performed by Gentille,Lynch,Linder \&Walsh 
(2003) the studies performing computer games for a long time have low performance in school.

Randel,Morris \&Wetzel (1992) reviewed 67 studies of the effect of computer instructional games in the mentioned studies as inconsistent. Hays (2005) reviewed 48 studies and achieved similar results. Vansickle (1986) in a study "A quantitative review of research on instructional gaming: A twenty-year perspective" reviewed 26 studies and stated the result positive and weak.

Despite the research evidences, some studies showed that computer games had no effect on academic performance of users. Ahmadi (1998) in a sample of male third of guidance school in Isfahan city found that the students performing computer games are similar to the students from academic aspects not performing these games. In another study done by Ghatrifi et al., (2006), there was no significant difference between academic performance of three groups of guidance school students of Tehran (the group not using computer games, the group using less and the group using much). The results of study showed that there was no correlation between the application of micro-computers and academic performance (Dominick, 1984; cited in Gunter, 1997/2008). Other studies supported the positive effects of computer games on cognitive and academic performance of players. Pourmohseni, Vafayi and Azad Falah (2004) showed that computer games increased mental rotation (spatial ability) of first and second of guidance school students. McClurg \& Chaille (1987), Miller \&Kapel (1985) reported similar results.

Anderson et al., (2004, cited in Ghatrifi et al., 2006) cited some researches as emphasizing the positive effects of computer games in training and health (Rinkon et al., 1983), enrichment of educational environment (Simon, 1985), increasing learning motivation of students (Kelly et al., 1994), simulation of various situations in education affairs as stock market and air traffic control (Rutter et al., 1983). Dempsey, Rasmussen \& Lucassen.

(1994) reviewed 94 studies regarding the effect of video instructional games as positive. Vogel et al., (2006) reviewed 32 studies and found the instructional effects of these games as positive.

Based on the different nature of specific academic fields, some researchers have evaluated the effect of computer games on performance of users in special fields. One of the fields is mathematics. Mathematics is one of the effective textbooks in academic and job future of people and it is one of the textbooks as with great applications in routine life. There are a few studies regarding the effect of computer games on performance of users in math field. Wei,Sopory \&Hendrex (2009) evaluated the effect of competitive and noncompetitive educational mathematics computer games of four- to seven-year-old boys' and girls' recall of game-playing experience. The results showed that learning of boys and girls was increased after competitive and non-competitive games.

These games had high influence on learning of girls. In another study done by Ke (2005) in a sample of 125 fifth graders' as assigned to Teams-Games-Tournament cooperative game-playing, interpersonal competitive game-playing, and no-games conditions. It was found that cooperative game-playing was most effective in promoting math learning compared to interpersonal competitive game playing. In another study done by Scottish researchers on 600 students in 32 schools, some students performed their games for $20 \mathrm{~min}$ for 9 weeks at the start of math classes as reading the tests, problem solving and memory strengthening games. The analysis of results of tests at the beginning and end of classes showed that the score of students using computer games was improved $50 \%$. After statement of the results of Scotland education organization, computer games reduced class-education gap and all students were at the same math learning level (Computer games", September 25, 2008). Hong \& Liu(2003) emphasized that computer games increased problem solving. In a study done by Ledman \& Niess (1999), the researchers stated that computers can help the students to study math and sciences in realistic world. According to authors, math should be reliable and realistic.

Leigh (2004) showed that computer games could improve cognitive skills and problem solving. They stated that if children love computer games, teachers should make computer math games that students can do computations with computer. These games include some strategies to increase knowledge of students. Computer games should present immediate feedback and test skills are developed. These games are used as an alternative for practice.

Based on the increasing inclination of students to computer games on one hand and the inconsistent results on other hand, in the previous studies regarding the effect of these games on academic performance of players, it is required that researchers perform more studies in this regard. The present study is also performed for this aim. In most of the studies, the effect of computer games on academic performance of students is investigated as general and less is considered about the effect of these games on performance of students in specific textbooks. Also, in most of the studies, the effect of computer games is investigated without separating its different types. This study attempted to close this gap. The present study aimed to investigate the effect of war and sport computer games on performance of students in math.

\section{Methodology}

Study method: This study applied comparative ex post facto method. 
Study population: The study population includes all male fourth grade of primary school of state schools of Behbahan city.

Sample: Random clustering sampling method is used and two male primary schools are selected among primary male state schools of Behbahan city. The selected schools had three fourth grade classes. Of each school, two fourth grades were selected randomly as sample of study $(n=128)$.

Data collection methods: For data collection, two methods of math test and structured interview were applied. The test in this study includes 12math items. For content validity, at first a Table of textbook features (test table) is provided for $54 \%$ of fourth grade of primary school math book. Based on this Table, 12 various items of math including four main actions, geometry and verbal issues are provided. Questions were given to two analyzers (teacher of fourth grade) to state their views regarding their relevance and suitability. These two analyzers taught in some classes except the selected classes for sample. The corrections were made by two analyzers. Then, the test was performed in fourth grade not included in sample of study. The final form of test was provided based on the opinion of analyzers and results of initial study. A key test with analytical scoring method was provided for test to minimize the mistakes in scoring in corrections. The correlation coefficient between the scores of test with math score of first period of students in their results form was $0.674(\mathrm{P}=0)$. To compute reliability, half split method was used. The correlation coefficient of half split (odd and even method) and correction with Spearman-Brown formula was 0.88. For data collection of computer games, individual structured interview method was used. The following questions were asked in each interview:

First name and last name, 2- Do you play computer games, 3- How often do you play? Make a list of all your games. As the term computer was common for students, this term was used.

Procedure: The test took $35 \mathrm{~min}$ and the researcher and teachers were also present. After the procedure, the sheets of students were corrected with a pre-defined key as defined with scoring analytical method and the score of each question was defined. At first, the students were divided into two groups: 1- The group using computer games as daily or two days alternatively for 0.5 hours $(n=62), 2$ - The group not using computer games generally or doing them at summer $(n=66)$. The mean of achieved score in math test was compared with independent t-test with each other. Then, the first group was divided into the students performing war games (e.g. generals and counter) $(n=35)$ and the group doing sport games (e.g. Football, 2008, 2010) $(n=27)$. The mean of math scores is war games with the man of math scores and sport games group were compared with independent t-test.

\section{Results}

To compare the mean of the group using computer games as daily or each two days at least for 0.5 hours and the group not using computer games or playing only at summers, independent t-test was used. The results of this comparison are shown in Table 1.

Table 1. The summary of results of T-test to compare the mean of scores of math test of computer games and no-game group

\begin{tabular}{|c|c|c|c|c|c|c|c|}
\hline $\mathrm{p}$ & t-value & Degree of freedom & Mean standard error & SD & Mean & $\mathrm{N}$ & Group \\
\hline \multirow{3}{*}{$\mathrm{p}>0.001$} & \multirow{3}{*}{3.52} & 126 & 0.358 & 2.82 & 17.51 & 62 & Computer games \\
\cline { 3 - 8 } & & 0.489 & 3.81 & 15.42 & 66 & No-computer game \\
\hline
\end{tabular}

The results in Table 1 show that the mean of math scores of computer game groups is significantly higher than the mean of math scores of students without computer games $(P<0.001)$. The mean of math scores of the students performing war games (general, counters) and the group performing sport games (e.g. football 2008, 2010) is compared with independent t-test and the results of this comparison are shown in Table 2.

Table 2. The summary of results of t-test to compare the mean of math test scores of war computer games and sport computer games

\begin{tabular}{|c|c|c|c|c|c|c|c|}
\hline $\mathrm{p}$ & $\mathrm{t}$-value & Degree of freedom & Mean standard error & $\mathrm{SD}$ & Mean & $\mathrm{N}$ & Group \\
\hline \multirow{2}{*}{$\mathrm{p}=0.482$} & \multirow{2}{*}{0.71} & \multirow{2}{*}{60} & $0.472 /$ & 2.79 & 17.74 & 35 & War computer games \\
\cline { 4 - 8 } & & 0.554 & 2.88 & 17.22 & 27 & Without sport computer game s \\
\hline
\end{tabular}

The results in Table 2 show that the mean of math scores of students in war computer games didn't have significant 
difference with the mean of math scores of sport computer games $(P=0.482)$.

\section{Discussion and Conclusion}

The results of study showed that the students using war or sport computer games daily or each day alternatively had high scores in math compared to the students not using computer games or those using only at summers. The difference of mean of scores of these two groups in math test was 2.09 and this had considerable significant difference $(P<0.001)$. These results were consistent with the results of study of Wei et al., (2009), Lederman, N., Niess (1999) and Leigh (2004). IN a study done by Scottish researchers (2008), similar results were achieved. Also, Ke (2005) found that cooperative game-playing was most effective in promoting math learning. How can we explain positive effects of computer games (or video) on progress of students in math?

First, computer games improve spatial ability of players. For example, Pourmohseni et al., (2004) showed that computer games increased mental rotation ability (spatial ability) of first and second of guidance school. McClurg \& Chaille (1987), Miller and Copel (1985) reported simialr results. On the other hand, spatial ability had close relationship with math achievement. Many researchers supported this association. For example, Fennema (1979, cited in Vangardren (2006) showed that spatial ability was correlated with performance indices sin math. The researchers showed that this ability was an important factor in special fields as math, geometry and problem solving (Burnett, Lane \& Dratt, 1979; Grobecker \& Delsi 2000; Kafmann 1990, cited in Vangardren (2006).

Second, based on Greenfield hypothesis (1984, 1983, cited in Gunter, 1997/2008), playing arcade-style action games could develop skills in inductive discovery, problem-solving through trial and error learning and the ability to understand, manipulate and control visual events on screen. These games could also facilitate the transfer of skills to other tasks requiring the same sorts of cognitive skills.

Third, learning method in computer or video games is trial and error method. Greenfield (1983/1984/1993, cited in Gunter 1997/2008, p.30) and one of the key points about video games was that players' group had to pick up the rules through trial and error and the testing of hypotheses rather than by being told in advance. This made them a powerful source of cognitive learning and skills acquisition. Players must figure out what difference symbols and items on screen meant or represented and how they behaved. In this way, video games encouraged a style of thinking that resembled the kind of reasoning and deductions scientists had to make when investigating an issue for the first time.

Fourth, as it was said, the games were effective tools to teach complex ideas as (a), practice is used instead of explanation, (b) it leads to personal satisfaction and motivation, (c) It presents various learning skills and styles, (d), mastery is promoted, (e) the texts are presented as interactive and users can decide for themselves (Charles \& McAlister, 2004; Holland et al., 2002).

Another finding of study showed the lack of significant difference between war and sport games in terms of the effect on improvement of math performance of students. We can say, the above mentioned items were true about two games. Both kinds of games had the above features.

Based on the findings of study, it is proposed that teachers on one hand and manufacturers of computer games on the other hand, apply the facilities of these games to teach basic skills in learning math.

Another important point is that findings of study are about cognitive and math fields. Thus, generalizing the results to personality fields is not true. Regarding the positive and negative effects of computer games and duration of these games on various aspects of children and adolescents, various researchers performed the studies and their results should be considered by parents.

\section{References}

Jensen, Eric. 2005. Brain and education. Translated by Leili Mohammad Hossein and Sepide Razavi. Tehran. School. Publication in original date, (2001).

Ghatrifi, Maryam; Rashid, Khosro, Delavar, Ali. (2006). The investigation of the effect of computer games on mental health and academic performance of girl and boy students of guidance school in Tehran city. Journal of psychology and educational sciences. No. 3. P.1-18.

Ahmadi, Sirus. 1998. The investigation of social effects of computer games on male students of third of guidance school of Isfahan city.

Pourmohseni, Fereshte; Vafayi, Maryam, Azad Falah, Parviz. 2004. The effect of computer games on mental rotation ability of adolescents. Journal of psychological sciences. NO. 3, 4. p. 75-84.

Gunter, B., 2008. Video and computer games effect on children. Translated by Hassan Pourabedini Nayini. Tehran. Javane Roshd. Publication date in original language, 1997).

Anderson, C.A., \& Karen.E.D. (2002). Video games and aggressive thoughts, feelings and behavior in the laboratory and life. Journal of 
Personality and Psychology, 78 (4).

Durkin, k \& Barber, B. (2002). Not so doomed: computer game play and positive adolescent developement. Journal of Applied Developmental Psychology, 23, 373 - 392.

Computer games boosts math's scores. Http: // newsbbc. Co. uk 12/ hi / uk-news / Scotland / 7635404. stm \{25 september 2008\} 12: 32, Thursday.

Gentile, D.A., Lynch, P.T., Linder, J. R., \& Walsh, D.A. (2003). The effects of violent video game habits on adolescent hostility, aggressive behaviors and school performance. Journal of Adolesence, 27 (1).

Charles, D., McAlister, M. (2004). Integrating Ideas about Invisible Playgrounds from Play Theory into Online Educational Digital Games. M. Rauterberg (Ed.): ICEC 2004, LNCS 3166, pp. 598 - 601.

Dempsey, J.V., Rasmussen, K., Lucassen, B. (1994). Instructional gaming: implications for instructional technology. Paper presented at the Annual Meeting of the AECT, 16-20 February, Nashville, TN.

Hays, R. T. (2005). The effectiveness of instructional games: A literature review and discussion. Naval Air Warfare Center Training Systems Division (No 2005-004). Retrieved 14 February 2010 from http://stnet.dtie.mil/oai/

Holland, W., Jenkins, H., Squire, K. (2002). Video game theory. In Perron, B., and Wolf, M. (Eds). Routledge. Retrieved14 February 2010 from http://www.educationarcade.org/gtt/

Hong, J. C., \& Liu, M. C. (2003). A study on thinking strategy between experts and novices of computer games. Computers in Human Behavior, 19 (2), $245-258$.

Ke,F.(2005).The effects of using computer games under different configurations of fifth graders' math achievement In C.Crawford et al.(Eds.), proceedings of Society for Information Technology \&Education International Conference 2005(pp.3697-3700).

Kebritchi, M. Hirumi. A, \&Bai.H. (2008). the effects of modern math video games on student math achievement and math course motivation; Research brief. Unpublished dissertation. College of Education, Department of Educational Technology, Research and Leadership. University of Central Florida.

McClurg, P.A., \&Chaille. C. (1987).Computer games: Environments for developing spatial cognition. Journal of Educational Computing Research, 3, 95 - 111.

Randel, J.M., Morris, B.A.,Wetzel, C.D., \&Whitehill, B.V. (1992). The effectiveness of games for Educational purposes: a review of recent research. Simulation and Gaming, 23(3), 261 - 276.

VanGardren.D. (2006). Spatial visualization, Visual imagery and mathematical problem solving of students with varying abilities. Journal of Learning Disabilities, 39(6). 496-506.

Van Sickle, R. L. (1986). A quantitative review of research on instructional gaming: A twenty-year Perspective. Theory and Research in Social Education, 14(3), 245-264.

Vogel, J. J., Vogel, D. S., Cannon-Bowers, J., Bowers, C.A., Muse, K., \& Wright, M. (2006). Computer Gaming and interactive simulations for learning: A meta-analysis. Journal of Educational Computing Research, 34(3), 229-243.

Leigh, C. (2004). It's all in the game. ProQuest Education Journals.80 (2), 59-64.

Lederman, N., Niess, M. (1999). Is it live or is it Memorex? ProQuest Education Journals. 99(7), 357-359.

Wei, F.F.,Sopory,P.,\& Hendrex, K.G. (2009).The effects of educational computer games on preschool children's learning; Gender differences playing completive and non-completive mathematics games. Paper presented at the annual meeting of the international communication association, Dresden .international congress center, Dresden, Germany online<PDF>.2009-05-25 from http://www.allacademic.com/meta/p91658-index.html. 